NBER WORKING PAPER SERIES

\title{
AN OPTIMIZING IS-LM FRAMEWORK WITH ENDOGENOUS INVESTMENT
}

\author{
Miguel Casares \\ Bennett T. McCallum \\ Working Paper 7908 \\ http://www.nber.org/papers/w7908
NATIONAL BUREAU OF ECONOMIC RESEARCH
1050 Massachusetts Avenue
Cambridge, MA 02138
September 2000

The first version of this paper was written while Casares was a visiting scholar at the Graduate School of Industrial Administration, Carnegie Mellon University. The authors thank Andrew Abel. Michael Dotsey, Alexander Wolman, and Michael Woodford for helpful comments. The views expressed are those of the authors and not necessarily those of the National Bureau of Economic Research.

(C) 2000 by Miguel Casares and Bennett T. McCallum. All rights reserved. Short sections of text, not to exceed two paragraphs, may be quoted without explicit permission provided that full credit, including $(\mathbb{C}$ notice, is given to the source. 
An Optimizing IS-LM Framework with Endogenous Investment

Miguel Casares and Bennett T. McCallum

NBER Working Paper No. 7908

September 2000

JEL No. E10, E30, E22

\section{$\underline{\text { ABSTRACT }}$}

Dynamic optimizing models with an IS-LM-type structure and slow price adjustments have been used for much recent monetary policy analysis, but usually with capital and investment treated as exogenous - a significant restriction. This paper demonstrates that investment decisions can be endogenized without undue complexity in such models and that these can be calibrated to provide reasonably realistic dynamic behavior. It is necessary, however, to include capital adjustment costs; models with no adjustment costs match cyclical data very poorly. Indeed, their match is considerably poorer than models with constant capital. The paper also finds that the preferred adjustment-cost specification is not close to quadratic.

\section{Miguel Casares}

Department of Economics

Public University of Navarra

31006 Pamplona, Spain

Fax. (+34) 948169721

mcasares@unavarra.es

Bennett T. McCallum

Graduate School of Industrial Administration

Carnegie Mellon University

Pittsburgh, PA 15213 USA

Tel. (412) 268-2347 Fax. (412) 268-7357

and NBER

bm05@andrew.cmu.edu 


\section{Introduction.}

Numerous recent papers have effectively utilized dynamic macroeconomic models with optimizing behavior that can be expressed in terms of relationships that are similar in many respects to traditional models of the "IS-LM" variety. Some noteworthy examples of such papers include Clarida, Galí and Gertler (1999), Kerr and King (1996), Galí and Gertler (1999), Jeanne (1998), Koenig (1990), McCallum and Nelson (1999a, 1999b), Rotemberg and Woodford $(1997,1999)$, and Woodford $(1995,1999)$, plus discussions in the textbook of Walsh (1998). ${ }^{1}$ The main difference between the models in these papers and semi-traditional IS-LM formulations - i.e., ones that distinguish between real and nominal interest rates ${ }^{2}$ is that the counterpart of the IS function includes an additional term (with a unit, coefficient) involving expected future expenditure.

The inclusion of this term gives a forward-looking aspect to expenditure decisions, a feature that, will typically result in significantly altered dynamic behavior in these models, relative to the semi-traditional type. Of course, these recent optimizing models still possess significant limitations. ${ }^{3}$ One of the more notable weaknesses is that capital investment is typically taken to be either non-existent (e.g., Woodford (1995)) or exogenous (e.g., McCallum and Nelson (1999b)). ${ }^{4}$ Clearly, this limitation is quite significant. ${ }^{5}$ Not only does it eliminate the possibility of studying issues relating to capital formation and growth, but in addition it removes the possibility of explain-

\footnotetext{
${ }^{1}$ This list includes only papers that use or mention the IS-LM terminology. There are numerous other papers with related models that make no such mention, including Goodfriend and King (1997), Kimball (1995), King and Wolman (1996,1999), and Yun (1996).

${ }^{2}$ The IS-LM setups that we will be concerned with are ones that are intended to represent only the aggregate demand portion of a macroeconomic system, not ones that treat the price level as a constant. In such models, real and nominal interest rates are clearly distinguished. For more discussion, see McCallum and Nelson (1999a).

${ }^{3}$ Most of the models being referred to are ones in which product prices are presumed to adjust slowly. There is much disagreement concerning various models of price adjustment, but in this paper we wish to focus upon limitations to the "IS-LM" portion of the model, not the "AS" portion (AS representing aggregate supply).

${ }^{4}$ There are some exceptions, including Kollmann (1999), King and Wolman (1996), and Yun (1996).

${ }^{5}$ For some purposes this weakness may not be serious, as is argued by McCallum and Nelson (1999a), but for others it can be crucial.
} 
ing endogenously the contrasting variability of consumption and investment spending, a contrast featured in much of the real business cycle literature.

The first purpose of the present paper is to extend the basic optimizing IS-LM framework so as to incorporate endogenous investment. This extension results in a model with an IS "sector" rather than an IS function, but retains much of the attractive simplicity of the exogenous-investment models and continues to facilitate a similar conceptual organization of behavioral forces. A priori, it would seem likely that for capital and investment movements to be even moderately realistic, it might be necessary to posit some form of adjustment costs. Initially we focus on a particularly simple specification used by Abel (1983) but in addition consider a more familiar version. ${ }^{6}$ For purposes of realism, the model presented includes sluggish adjustment of prices and inflation rates; in that regard we utilize a price-adjustment assumption related to that of Fuhrer and Moore (1995), which can be viewed as an ad hoc generalization of the more theoretically-justifiable specification of Rotemberg (1982) and Calvo (1983). ${ }^{7}$ To represent the medium-of-exchange role of money, we utilize a specification, very common in the recent literature, in which the period utility function is separable in terms of consumption and (the services of) real money balances. This specification is less plausible than ones involving a non-separable transaction-cost function, but the differences are insignificant for present purposes, as we explain in Section 2.

Besides developing this extension, the paper explores various related issues. One of considerable importance is whether enrichment of the optimizing IS-LM framework, so as to incorporate endogenous investment, has a major impact on properties of the model that are crucial for the study of alternative monetary policy rules. Does output, for example, respond differently in terms of its magnitude and/or dynamic pattern to a monetary policy shock? Or a technology shock? A second principal objective of the paper, accordingly, is to conduct an investigation of this issue. In addition, we explore the idea that investment adjustment costs are necessary to avoid unrealistic movements of capital and investment magnitudes. In the process of doing

\footnotetext{
${ }^{6}$ It is worth noting that with adjustment costs recognized, capital becomes a distinct asset differing from government and private bonds, even abstracting from unccrtainty.

${ }^{7}$ Recently this model has been the subject of considerable interest and controversy; see Walsh (1998: pp 224-26), Galí and Gertler (1999), Sbordone (1998), and Estrella and Fuhrer (1998).
} 
so, we obtain results suggesting that such costs are necessary but that the relatively familiar quadratic specification is inadequate.

None of the paper's analysis depends, of course, on use of the IS-LM terminology, which some economists find attractive and others find objectionable. Our own use of these terms is partly motivated by a desire to illustrate that actual analytical differences between proponents and opponents of "IS-LM analysis" can easily be overstated.

Organizationally, we begin in Section 2 with the specification of a model of the type typically used in the recent papers featuring dynamic optimizing models of the IS-LM type. Then in Section 3 we extend the setup so as to include endogenous investment with - and, partly for comparative purposes, without - adjustment costs. Section 4 is devoted to a quantitative calibration of the three model variants, and their dynamic properties are compared in Section 5. Extensions are presented in Section 6 and a short summary appears as Section 7.

\section{Reference Model with Exogenous Investment.}

We begin by specifying a typical model of the optimizing IS-LM form in which investment is not determined endogenously. Thus, we consider an economy populated by a large number of households making decisions in the presence of uncertainty about the future. A typical household seeks at time $t$ to maximize the intertemporal utility function

$$
E_{t} \sum_{j=0}^{\infty} \beta^{j} U\left(c_{t+j}, m_{t+j}, v_{t+j}, \zeta_{t+j}\right)
$$

where $\beta=(1+\rho)^{-1}, \rho>0$, is the household's discount factor; $c_{t}$ is consumption during $t$, and $m_{t}$ is the stock of real money balances at the end of $t .^{8}$ Also, $E_{t}$ is the expectation operator conditional on information (assumed complete) available in period $t$. Preference shocks $v_{t}$ and $\zeta_{t}$ enter the utility function in ways that will be specified below. Different households produce different goods; for the typical household $c_{t}$ represents a Dixit-Stiglitz (1977)

\footnotetext{
${ }^{8}$ We could alternatively let $m_{t}$ denote real balances at the beginning of $t$. This would result in a slightly different money demand function analogous to (14) below; on this point see McCallum and Nelson (1999a).
} 
index denoting the number of bundles consumed. The reason that $m_{t}$ appears in $U($.$) is that holdings of the economy's medium of exchange yield$ transaction services that reduce the amount of time or material resources needed for "shopping" - i.e., conducting transactions - for the many goods that comprise consumption bundles. Such effects are often represented indirectly by inclusion of $m_{t}$. It would not alter our results substantially to use a theoretically preferable formulation that specified explicitly the time or material resources that are needed for conducting transactions, with the amount needed negatively dependent upon the quantity of real money balances held. (For details, see Casares (2000) and McCallum (1999b)). If the relevant cost function is not separable in $c_{t}$ and $m_{t}$, there would then be implications as discussed below in footnote 13 .

The typical household's production of its specialized output is governed by the production function $y_{t}=f\left(A_{t} n_{t}, k_{t}\right)$, where $A_{t}$ is a labor-augmenting technology shock, $n_{t}$ is labor input, and $k_{t}$ is the stock of capital held at the start of $t .^{9}$ This production function $f($.$) is homogeneous of degree 1$ in its two inputs. Sales of the household's specialized output are restricted by the demand function $Y_{t}^{A}\left(P_{t} / P_{t}^{A}\right)^{-\theta}$, where $Y_{t}^{A}$ is aggregate demand, $P_{t}$ is the money price of the household's product, and $P_{t}^{A}$ is the aggregate price level. The household inelastically supplies one unit of labor per period to a labor market from which households purchase labor inputs at the real wage rate $w_{t}$. Finally, $b_{t+1}$ is the number of one-period government bonds purchased in $t$. Their real price is $\left(1+r_{t}\right)^{-1}$ and each is redeemed in $t+1$ for enough money to purchase one unit of consumption. Letting $\pi_{t}=\left(P_{t}^{A} / P_{t-1}^{A}\right)-1$ denote the inflation rate in period $t$, the household's budget constraint for period $t$ can be written as

(1) $Y_{t}^{A}\left(P_{t} / P_{t}^{A}\right)^{1-\theta}-t x_{t}-w_{t}\left(n_{t}-1\right)=c_{t}+k_{t+1}-(1-\delta) k_{t}+m_{t}-(1+$ $\left.\pi_{t}\right)^{-1} m_{t-1}+\left(1+r_{t}\right)^{-1} b_{t+1}-b_{t}$

with production equal to quantity demanded

(2) $f\left(A_{t} n_{t}, k_{t}\right)=Y_{t}^{A}\left(P_{t} / P_{t}^{A}\right)^{-\theta}$

\footnotetext{
${ }^{9}$ Below we introduce a market in capital goods.
} 
and with similar constraints applying expectationally for all future periods. In (1), t $x_{t}$ denotes lump-sum taxes (net of transfers) levied on the household while $\delta$ is the capital depreciation rate. and ${ }^{10}$

In this setting, the household's optimality conditions include (1), (2):

(3) $U_{1}\left(c_{t}, m_{t}, v_{t}, \zeta_{t}\right)-\lambda_{t}=0$

(4) $U_{2}\left(c_{t}, m_{t}, v_{t}, \zeta_{t}\right)-\lambda_{t}+\beta E_{t}\left[\lambda_{t+1}\left(1+\pi_{t+1}\right)^{-1}\right]=0$

(5) $-\lambda_{t} w_{t}+\xi_{t} A_{t} f_{1}\left(A_{t} n_{t}, k_{t}\right)=0$

(6) $-\lambda_{t}+\beta E_{t} \lambda_{t+1}(1-\delta)+\beta E_{t}\left[\xi_{t+1} f_{2}\left(A_{t+1} n_{t+1}, k_{t+1}\right)\right]=0$

(7) $-\lambda_{t}\left(1+r_{t}\right)^{-1}+\beta E_{t} \lambda_{t+1}=0$.

(8) $\lambda_{t} Y_{t}^{A}(1-\theta) P_{t}^{-\theta} /\left(P_{t}^{A}\right)^{1-\theta}+\xi_{t} Y_{t}^{A} \theta P_{t}^{-(\theta+1)} /\left(P_{t}^{A}\right)^{-\theta}=0$.

Assuming that the relevant transversality conditions are satisfied, these eight relations determine the household's choices of $c_{t}, m_{t}, n_{t}, k_{t+1}, b_{t+1}, P_{t}, \xi_{t}$, and $\lambda_{t}$ given the values of $\pi_{t}, w_{t}, r_{t}$, and $t x_{t}$ that it faces.

For general equilibrium, the government's budget constraint must also be satisfied. In per-household terms, it is

(9) $g_{t}-t x_{t}=m_{t}-\left(1+\pi_{t}\right)^{-1} m_{t-1}+\left(1+r_{t}\right)^{-1} b_{t+1}-b_{t}$,

where $g_{t}$ denotes government consumption of goods and services. In addition, there are the market-clearing conditions

(10) $n_{t}=1$

and

\footnotetext{
${ }^{10}$ Here and below, $f_{i}($.$) represents the partial derivative of the function f($.$) with respect$ to its $i$-th argunent.
} 
(11) $m_{t}=\frac{M_{t}}{P_{t}}$

where $M_{t}$ is the per-household nominal money supply, and also the identity

(12) $\pi_{t}=\frac{P_{t}^{A}}{P_{t-1}^{A}}-1$

Assuming symmetry across households, $P_{t}=P_{t}^{A}$ will hold in equilibrium. Then we have eleven conditions (apart from the relevant transversality conditions) to determine the time paths of $c, m, n, k, b, \lambda, \xi, w, r, \pi$, and $P$ in response to exogenous, government-chosen paths of $M_{t}, g_{t}$ and $t x_{t}$. Alternatively, the government could be thought of as determining $b_{t}$ instead of $g_{t}$ or $t x_{t}$, with the other variable becoming endogenous. Similarly, the government could implement monetary policy by means of the nominal interest rate $R_{t}$, defined by $1+R_{t}=\left(1+r_{t}\right)\left(1+E_{t} \pi_{t+1}\right)$, instead of $M_{t}$.

To express this system in an IS-LM fashion, we combine (3) and (7) to yield

$$
U_{1}\left(c_{t}, m_{t}, v_{t}, \zeta_{t}\right)=\beta E_{t}\left[U_{1}\left(c_{t+1}, m_{t+1}, v_{t+1}, \zeta_{t+1}\right)\right]\left(1+r_{t}\right)
$$

and also combine (3), (4), (7), and the definition of $R_{t}$ to yield

(14) $U_{2}\left(c_{t}, m_{t}, v_{t}, \zeta_{t}\right)=U_{1}\left(c_{t}, m_{t}, v_{t}, \zeta_{t}\right) \frac{R_{t}}{1+R_{t}}$

Next we assume that the period utility function can be expressed or approximated by the form

$$
U\left(c_{t}, m_{t}, v_{t}, \zeta_{t}\right)=\Upsilon(1-\sigma)^{-1} \exp \left(v_{t}\right) c_{t}^{1-\sigma}+(1-\Upsilon)(1-\gamma)^{-1} \exp \left(\zeta_{t}\right) m_{t}^{1-\gamma}
$$


with $0<\Upsilon<1$ and $\sigma, \gamma>0$. Accordingly, we have $U_{1}\left(c_{t}, m_{t}, v_{t}, \zeta_{t}\right)=$ $\Upsilon \exp \left(v_{t}\right) c_{t}^{-\sigma}$ and $U_{2}\left(c_{t}, m_{t}, v_{t}, \zeta_{t}\right)=(1-\Upsilon) \exp \left(\zeta_{t}\right) m_{t}^{-\gamma}$. Then (13) reduces to

(16) $\exp \left(v_{t}\right) c_{t}^{-\sigma}=E_{t}\left[\exp \left(v_{t+1}\right) c_{t+1}^{-\sigma}\right] \beta\left(1+r_{t}\right)$

Here and below, we employ the techniques described extensively in Uhlig (1999) to obtain log-linear approximations to nonlinear relations such as (16). In doing so, "hat" variables are defined as (logarithmic) fractional deviations from steady-state values, e.g., $\widehat{c}_{t}=\log \left(\frac{c_{t}}{c^{s s}}\right)$ with the $s s$ superscript denoting the steady state value. Thus, equation (16) can be transformed into ${ }^{11}$

(17) $\widehat{c}_{t}=E_{t} \widehat{c}_{t+1}-\sigma^{-1}\left(r_{t}-r^{s s}\right)-\sigma^{-1}\left(E_{t} v_{t+1}-v_{t}\right)$,

We assume that the consumption preference shock follows the $\operatorname{AR}(1)$ process

(18) $v_{t}=\rho_{v} v_{t-1}+\varepsilon_{v t}$

with $\left|\rho_{v}\right|<1$ and $\varepsilon_{v t}$ drawn from a normal distribution, i.e., $\varepsilon_{v t} \sim N\left(0, \sigma_{\varepsilon_{v t}}\right)$. Substituting (18) into (17) and using $r_{t}=R_{t}-E_{t} \pi_{t+1}$ yields

$$
\widehat{c}_{t}=E_{t} \widehat{c}_{t+1}-\sigma^{-1}\left(R_{t}-E_{t} \pi_{t+1}-r^{s s}\right)+\sigma^{-1}\left(1-\rho_{v}\right) v_{t}
$$

Regarding the money demand formulation, for the utility function specification (15) the general expression (14) reduces to

$$
m_{t}=\exp \left(\gamma^{-1}\left(\zeta_{t}-v_{t}\right)\right) c_{t}^{\frac{\sigma}{\gamma}}\left[\frac{\Upsilon R_{t}}{(1-\Upsilon)\left(1+R_{t}\right)}\right]^{-\frac{1}{\gamma}}
$$

\footnotetext{
${ }^{11}$ Here we also use $\log \left(1+r_{t}\right) \simeq r_{t}$ and $\log \beta=-\log (1+\rho) \simeq-\rho=-r^{s s}$. Regarding the latter, note that in a Sidrauski-type optimizing model with no technological progress or population growth, the steady state real interest rate $r^{s s}$ is equal to the rate of intertemporal preference $\left(\rho=r^{s s}\right)$.
} 
which can be approximated by the semi-loglinearized relation ${ }^{12}$

(21) $\widehat{m}_{t}=\frac{\sigma}{\gamma} \widehat{c}_{t}-\frac{1}{\gamma R^{s s}}\left(R_{t}-R^{s s}\right)+\frac{1}{\gamma}\left(\zeta_{t}-v_{t}\right)$.

Defining the composite disturbance $\chi_{t}=\frac{1}{\gamma}\left(\zeta_{t}-v_{t}\right)$, equation (21) becomes the following money demand expression:

(22) $\widehat{m}_{t}=\frac{\sigma}{\gamma} \widehat{c}_{t}-\frac{1}{\gamma R^{s s}}\left(R_{t}-R^{s s}\right)+\chi_{t}$.

Clearly, (22) is of the familiar "LM" form, in which real balances demanded depend positively upon a transaction variable and negatively upon an opportunitycost variable.

Next, to put (19) into an "IS" form, let us first suppose - as in Woodford (1995) and elsewhere - that $k_{t+1}$ is not a variable but is fixed at the value $k$. Then the relation (6) becomes inapplicable and we can write the overall resource constraint

$$
f\left(A_{t} n_{t}, k_{t}\right)=c_{t}+k_{t+1}-(1-\delta) k_{t}+g_{t}
$$

as

(24) $y_{t}=c_{t}+\delta k+g_{t}$

For a loglinear approximation to (24) we take

(25) $\widehat{y}_{t}=\omega_{1} \widehat{c}_{t}+\omega_{2} \widehat{g}_{t}$

\footnotetext{
${ }^{12}$ Here we use $R_{t} \simeq \frac{R_{t}}{1+R_{t}}$.
} 
where $\omega_{1}$ and $\omega_{2}$ are the steady-state shares in output of consumption and government expenditure, i.e., $\omega_{1}=c^{s s} / y^{s s}$ and $\omega_{2}=g^{s s} / y^{s s}$. Then substitution of (19) into (25) results in

$$
\widehat{y}_{t}=E_{t} \widehat{y}_{t+1}-\frac{\omega_{1}}{\sigma}\left(R_{t}-E_{t} \pi_{t+1}-r^{s s}\right)+\omega_{2}\left(\widehat{g}_{t}-E_{t} \widehat{g}_{t+1}\right)+\frac{\omega_{1}\left(1-\rho_{v}\right)}{\sigma} v_{t}
$$

The latter is an "expectational IS function", in which demand for current output is expressed not only as a negative function of $r_{t}$, a positive function of $\left(\widehat{g}_{t}-E_{t} \widehat{g}_{t+1}\right)$, and a positive function of the consumption preference shock $v_{t}$, but is also related positively to $E_{t} \widehat{y}_{t+1}$ (hence the designation expectational). The presence of the last term represents the only significant, difference from a semi-traditional IS specification, but this difference can obviously be important for various dynamic issues. ${ }^{13}$

In a system such as (26) and (22), analysis of the IS-LM type can be carried out as follows. With exogenous processes specified for $M_{t}, \widehat{g}_{t}, v_{t}$, and $\chi_{t}$, equations (26) and (22) determine the behavior of $R_{t}$ and $\pi_{t}$, given the identities $m_{t}=M_{t} / P_{t}^{A}$ and $\pi_{t}=P_{t}^{A} / P_{t-1}^{A}-1$, plus the resource constraint (25). ${ }^{14}$ Alternatively, the monetary authority could specify the behavior of $R_{t}$, as central banks do in reality, in which case the model would determine the behavior of $M_{t}$.

In the flexible-price system just described, output $y_{t}$ fluctuates only because of the state of technology; it equals its "full-employment." value $\bar{y}_{t}=$ $f\left(A_{t} 1, k\right)$ in each period. Cyclical fluctuations in $y_{t}$ will be generated in a real-business-cycle fashion by means of an appropriate stochastic process for

\footnotetext{
${ }^{13}$ In the case that a transactions-cost formulation is used, as we suggested above, the IS-type function (26) will also include a term involving $\widehat{m}_{t}-E_{t} \widehat{m}_{t+1}$ unless the transaction cost function is separable. McCallum (1999b) suggests a plausible specification that is not separable. Quantitative calibration of the model's parameters suggests, however, that the coefficient attached to this term will be quite snall - e.g., less than 0.02. Accordingly, it would appear to be entirely satisfactory to neglect such effects for the purposes of the present paper.

${ }^{14}$ This argument does not imply that money- demand and saving behavior, representcd by $(22)$ and (26) respectively, are entirely independent, for the structural parameter $\sigma$ appears in both of these relations. Also, their disturbances may not be stochastic:ally independent.
} 
the technology term $A_{t}$. Note that in this case, the symmetry condition $P_{t}=P_{t}^{A}$ and equation (8) together imply that

$$
\xi_{t} / \lambda_{t}=(\theta-1) / \theta
$$

In addition, departures of $y_{t}$ from $\bar{y}_{t}$ can be introduced by positing that $P_{t}$ does not adjust fully within each period - i.e., by assuming price stickiness - and dropping the market-clearing condition $n_{t}=1$. Suppose, for example, that we add a Calvo-Rotemberg-type price adjustment equation

(28) $\pi_{t}=\beta E_{t} \pi_{t+1}+\phi\left(\widehat{y}_{t}-\widehat{\bar{y}}_{t}\right)$.

Then (22), (26) and (28) determine values of $\pi_{t}, R_{t}$, and $\widehat{y}_{t}-\widehat{\bar{y}}_{t}$ in response to the exogenous processes and identitites described above. Again, policy could specify behavior of $R_{t}$ in which case $M_{t}$ would be determined endogenously. In the exercises conducted below we shall, for the sake of realism, focus upon this latter case.

\section{Endogenous Investment.}

Now we are prepared to endogenize investment. Conceptually, this can be done straightforwardly by merely recognizing $k_{t+1}$ as a variable and including relation (6) in the system of first-order conditions. ${ }^{15}$ The resulting model is unrealistic, however, in that it implies much more volatility than exists in reality for capital, the marginal product of capital, and the marginal product of labor. This important weakness will be documented below.

It is possible to develop a well-behaved and tractable investment specification, nevertheless, by adopting the highly plausible assumption that the process of capital investment - i.e., of "installing" capital goods - requires the usage of some resources. Many previous studies have utilized such an

\footnotetext{
${ }^{15}$ Michael Woodford has pointed out to us that in some sticky price models producers are unable to adjust prices in some periods. Thus the expected value of an additional unit of capital in the next period is not simply the marginal product of capital times the marginal revenue as given by the producer's demand function. In what, follows, we assume that the sticky price formulation is not of this type.
} 
assumption, including Eisner and Strotz (1963), Lucas and Prescott (1971), and Hayashi (1982). An alternative approach would be to include exogenous "time to build" constraints, as in Kydland and Prescott. (1982) and many subsequent papers. We consider it methodologically preferable, however, to endogenize the postulated sluggishness of capital stock adjustments. The particular adjustment-cost specification that we begin with is taken from Abel (1983). Specifically, the assumption is that gross investment $x_{t}$, defined as

(29) $x_{t}=k_{t+1}-(1-\delta) k_{t}$,

entails adjustment costs $C\left(x_{t}\right)$ according to the formula

$$
C\left(x_{t}\right)=\psi x_{t}^{\eta} \quad \text { with } \quad \psi>0 \quad \text { and } \quad \eta>1 .
$$

Clearly, with $\eta=2$, (30) would amount to quadratic costs of adjustment. But other values of $\eta$ are permitted by (30), and as it happens our calibration (in Section 4) suggests a larger value. One point regarding $C\left(x_{t}\right)$ needs to be added, as follows. We intend that non-zero values of $x_{t}$ bring about positive adjustment costs, even if $x_{t}$ is negative. With some values of $\eta$ this would appear not to be the case: $(-1.5)^{3}=-3.375$, for example. Accordingly, we interpret $x_{t}^{\eta}$ to be evaluated as $\left(x_{t}^{2}\right)^{\frac{\eta}{2}}$. Thus, we have $\left[(-1.5)^{2}\right]^{1.5}=2.25^{1.5}=$ 3.375.

The functional form (30) implies increasing marginal adjustment cost. Since the production function $f($.$) is homogeneous of degree 1$, we have a production function net of adjustment costs $f\left(A_{t} n_{t}, k_{t}\right)-C\left(x_{t}\right)$ that implies decreasing returns to scale. In other words, the ratio of total adjustment costs to output would increase with the size of the production plant, discouraging the existence of large plants. In Section 6, an alternative adjustment cost specification will be introduced that has the property of constant returns to scale.

Recognition of adjustment costs implies that $-C\left(x_{t}\right)$ appears as an additional term on the left-hand side (lhs) of the household's budget constraint 
(1), and also on the lhs of the overall resource constraint (23). With this change, the first-order optimality condition with respect to $k_{t+1}$ (6) becomes, ${ }^{16}$ using (27) and the definition $\Theta=(\theta-1) / \theta$,

(31) $\lambda_{t}\left(1+C^{\prime}\left(x_{t}\right)\right)=\beta E_{t} \lambda_{t+1}\left[1+\Theta f_{2}\left(A_{t+1} n_{t+1}, k_{t+1}\right)-\delta+(1-\delta) C^{\prime}\left(x_{t+1}\right)\right]$.

For simplicity, let us denote next period's marginal product of capital $f_{2 t+1}=$ $f_{2}\left(A_{t+1} n_{t+1}, k_{t+1}\right)$. Using $\beta E_{t} \lambda_{t+1}=\lambda_{t}\left(1+r_{t}\right)^{-1}$ from (7), the household first. order condition regarding the choice of bond purchases, we obtain

$$
1+r_{t}=\frac{1+\Theta E_{t} f_{2 t+1}-\delta+(1-\delta) E_{t} C^{\prime}\left(x_{t+1}\right)}{1+C^{\prime}\left(x_{t}\right)}
$$

The left hand side of (32) is the return on the financial asset and the right hand side is the (expected) net return on the real asset, adjusted by the markup factor $\Theta$. Taking natural logarithms on both sides of (32) and assuming that the real interest rate, the marginal product of capital net of depreciation, and the marginal adjustment cost are small relative to $1,{ }^{17}$ we obtain the approximation

$$
C^{\prime}\left(x_{t}\right)=\Theta E_{t} f_{2 t+1}-\delta-r_{t}+(1-\delta) E_{t} C^{\prime}\left(x_{t+1}\right)
$$

With our adjustment cost specification (30), equation (33) implies the following non-linear relationship

$$
\psi \eta x_{t}^{\eta-1}=\Theta E_{t} f_{2 t+1}-\delta-r_{t}+(1-\delta) \psi \eta E_{t} x_{t+1}^{\eta-1}
$$

Again using Uhlig's (1999) linearization rules, we can approximate the latter with the following semi-loglinear investment equation

\footnotetext{
${ }^{16}$ Note that $C^{\prime}\left(x_{t}\right) \equiv \frac{\partial C\left(x_{t}\right)}{\partial x_{t}}=\frac{\partial C\left(x_{t}\right)}{\partial k_{t+1}}$ and $C^{\prime}\left(x_{t+1}\right) \equiv \frac{\partial C\left(x_{t+1}\right)}{\partial x_{t+1}}=\frac{-1}{1-\delta} \frac{\partial C\left(x_{t+1}\right)}{\partial k_{t+1}}$.

${ }^{17}$ That is, we use the approximation $\log (1+z) \simeq z$ for $z \ll 1$.
} 
(35) $\widehat{x}_{t}=(1-\delta) E_{t} \widehat{x}_{t+1}+\frac{1}{(\eta-1) C^{\prime}\left(x^{s s}\right)}\left(\Theta E_{t} f_{2 t+1}-\delta-r_{t}\right)$

where $C^{\prime}\left(x^{s s}\right)=\eta \psi\left(x^{s s}\right)^{\eta-1}$. This is an "expectational" investment equation in which the current period's investment depends on next period's expected investment and on the gap between the expected return on physical capital, adjusted by the factor $\Theta$, and the return on the financial asset. Let, $z_{t}$ denote this premium:

(36) $z_{t}=\Theta E_{t} f_{2 t+1}-\delta-r_{t}$

When we sequentially substitute out expected investment, equation (35) can be expressed as

(37) $\widehat{x}_{t}=\frac{1}{(\eta-1) C^{\prime}\left(x^{s s}\right)} E_{t} \sum_{j=0}^{\infty}(1-\delta)^{j} z_{t+j}$

Thus representation (37) of our investment equation indicates that current investment depends on current and all expected future premiums on investing in real assets. In addition, the value of $\frac{1}{(\eta-1) C^{\prime}\left(x^{s s}\right)}$ in $(35)$ is the semi-elasticity of investment with respect to (wrt) the real asset's premium. This number directly affects the variability of investment over the economic cycle. Clearly, both parameters of the adjustment cost function at hand influence the size of this number. To issustrate this influence, Table 1 reports figures of the semi-elasticity of the physical asset premium in (35) for various calibrations of the parameters $\psi$ and $\eta$ of the adjustment cost function. ${ }^{18}$

\footnotetext{
${ }^{18}$ The values reported in Table 1 depend on $x^{s s}$, which depends upon values of $\eta$, $\psi$, and other parameters. Numerical values for these are discussed below. Thus the presentation here of Table 1 is logically premature, but is made nevertheless to aid in understanding of the nature of the adjustment cost function.
} 
Table 1

Semi-elasticity of investment

wrt the real asset premium in equation (35)

$\begin{array}{ccccc} & \psi=0.1 & \psi=0.2 & \psi=0.3 & \psi=0.4 \\ \eta=2 & 7.16 & 4.10 & 3.04 & 2.48 \\ \eta=3 & 3.46 & 2.17 & 1.70 & 1.44 \\ \eta=4 & 2.42 & 1.61 & 1.29 & 1.22 \\ \eta=5 & 1.96 & 1.35 & 1.11 & 0.97\end{array}$

Thus a higher $\eta$ reduces the semi-elasticity wrt $z_{t}$ in the investment equation (35). It should be recalled that $\eta$ is the elasticity of the total adjustment cost with respect to investment. When this cost increases more rapidly with $x_{t}$, cyclical movements in investment will be more moderate. Likewise, a rise in the scale parameter $\psi$ increases the size of the adjustment cost and thus reduces the value of the semi-elasticity in (35). Notably, the absence of adjustment costs $(\psi=0)$ implies $C^{\prime}\left(x^{s s}\right)=0$ and an "infinite response" of investment to changes in the expected marginal product of capital premium in $(35){ }^{19}$

In order to parameterize the marginal product of capital, let. us assume that our production function is Cobb-Douglas:

$$
y_{t}=f\left(A_{t} n_{t}, k_{t}\right)=\left(A_{t} n_{t}\right)^{1-\alpha} k_{t}^{\alpha} \quad \text { with } \quad 0<\alpha<1
$$

Then, with the recognition of variable capital and investment adjustment costs, the system includes an "IS sector" consisting of

$$
\begin{gathered}
\widehat{c}_{t}=E_{t} \widehat{c}_{t+1}-\sigma^{-1}\left(R_{t}-E_{t} \pi_{t+1}-r^{s s}\right)+\sigma^{-1}\left(1-\rho_{v}\right) v_{t} \\
\widehat{x}_{t}=(1-\delta) E_{t} \widehat{x}_{t+1}+\frac{1}{(\eta-1) C^{\prime}\left(x^{s s}\right)}\left(\Theta E_{t} f_{2 t+1}-\delta-\left(R_{t}-E_{t} \pi_{t+1}\right)\right) \\
f_{2 t}=f_{2}\left(n^{s s}, k^{s s}\right)\left(\widehat{y}_{t}-\widehat{k}_{t}\right) \\
\widehat{k}_{t+1}=(1-\delta) \widehat{k}_{t}+\delta \widehat{x}_{t} \\
\widehat{y}_{t}=\omega_{1} \widehat{c}_{t}+\omega_{2} \widehat{g}_{t}+\omega_{3} \widehat{x}_{t},
\end{gathered}
$$

\footnotetext{
${ }^{19}$ Finite responses when $\psi=0$ can be calculated by solving an analogous model without explicit adjustment costs from installing capital. This will be done below considering the setup described in the previous section with capital variable and so using equation (6). Note that equations (6), (7), (8), and (27) imply together: $r_{t}=\Theta E_{t} f_{2 t+1}-\delta$, in contrast with the adjustment,-cost case.
} 
in which (39c) is the log-linear approximation to the marginal product of capital for our Cobb-Douglas functional form, (39d) is a loglinearised version of the investment definition (29), and (39e) is the overall resource constraint now including investment. Consumption decisions (39a), investment decisions (39b), and the amount of (exogenous) government purchases give rise to current real demand as in (39e). The value of $\omega_{3}$ in (39e) reflects the weight of investment in total output from a steady-state perspective $\left(\omega_{3}=\left(x^{s s}+C\left(x^{s s}\right)\right) / y^{s s}\right) \cdot{ }^{20}$

To determine the system's endogenous variables, this five-equation IS sector can be used together with the LM equation (22), and the specification of natural-rate output,

(40) $\widehat{\bar{y}}_{t}=(1-\alpha) \log A_{t}+\alpha \widehat{k}_{t}$.

These relations can then be combined with a price adjustment specification - full price flexibility or relation (28), for example - and policy rules for $\widehat{g}_{t}$, and either $M_{t}$ or $R_{t}$. The resulting eight relations will determine time paths of $\widehat{y}_{t}, \widehat{\bar{y}}_{t}, \widehat{c}_{t}, \widehat{x}_{t}, \widehat{k}_{t+1}, f_{2 t}, \pi_{t}$, and either $R_{t}$ or $M_{t}$.

\section{Calibration.}

In this section we complete the specification of our model in numerical terms, so as to permit quantitative analysis of its properties (considering several variants). One step is to adopt a monetary policy rule. For the sake of realism we will treat $R_{t}$ as the monetary authority's instrument variable, using a version of the well-known policy rule proposed by Taylor (1993). Studies by Clarida, Galí, and Gertler (1998) and others have indicated that estimated versions of this rule generally benefit from inclusion of the variable $R_{t-1}$, to reflect interest rate smoothing, with a positive coefficient in the vicinity of $0.75-0.85$. Accordingly, we represent monetary policy behavior as follows:

(41) $R_{t}=\left(1-\mu_{3}\right)\left[\left(1+\mu_{1}\right) \pi_{t}+\mu_{2} E_{t-1} \tilde{y}_{t}\right]+\mu_{3} R_{t-1}+\varepsilon_{R t}$.

\footnotetext{
${ }^{20}$ Note that the reported value of $\omega_{3}$ reflects the presence of adjustment - cost uses of output in the overall resource constraint.
} 
where $\varepsilon_{R t}$ is a policy shock. Here, and in what follows, $\widetilde{y}_{t}$ denotes $\widehat{y}_{t}-\widehat{\bar{y}}_{t}$, the fractional difference between output and its market-clearing or natural-rate value. We will refer to this as the output gap. In the model's variants with full price flexibility this gap measure never departs from zero. In the variants with slow price adjustments, however, the term represents policy feedback intended to stabilize $\widetilde{y}_{t}$ as in Taylor (1993) and Clarida, Galí and Gertler (1998). The response is applied in (41) to $E_{t-1} \widetilde{y}_{t}$ rather than $\widetilde{y}_{t}$ since actual central banks do not have observations on $\widehat{y}_{t}$ or $\widehat{\bar{y}}_{t}$ when setting $R_{t}$.

For the same reason it would be desirable to utilize $E_{t-1} \pi_{t}$ or $E_{t-1} \pi_{t+j}$ rather than $\pi_{t}$ itself in (41). In the case with full price flexibility, however, this would lead to a form of price level indeterminacy, because the relevant portion of the model would then include no reference to the current inflation rate. Thus we have assumed that $\pi_{t}$ appears in (41) so as to be able to use the same policy rule for flexible and sticky-price variants. This departure from operationality in the specification is not extremely serious since percentage forecast errors are much smaller for $\pi_{t}$ than for $\widetilde{y}_{t}$ in actual economies. For parameter values we adopt $\mu_{1}=0.5, \mu_{2}=0.1$, and $\mu_{3}=0.8$ as in McCallum (1999a).

Next we discuss the price adjustment model to be used in the stickyprice variants. Although we have mentioned the Calvo-Rotemberg formula (28) above, in our quantitative analysis we will utilize a related specification, variants of which have been discussed by Fuhrer (1996), Walsh (1998), Gali and Gertler (1999), and McCallum (1999a), among others. This generalization incorporates the lagged inflation rate, and in some versions a lagged output gap as well. The particular version used below can be written as

$$
\pi_{t}=\phi_{0} E_{t} \pi_{t+1}+\left(1-\phi_{0}\right) \pi_{t-1}+\phi_{1} \widetilde{y}_{t}+\xi_{t}
$$

where $\xi_{t}$ is a white noise shock. Indeed, we will set $\phi_{0}=0.5$, in which case (42) becomes quite similar to a two-period version of the model developed by Fuhrer and Moore (1995), ${ }^{21}$ which imparts a degree of inertia to the inflation rate that is rather similar to that observed in actual economies. On this point, see Fuhrer and Moore (1995), Nelson (1998), and Walsh (1998). For

\footnotetext{
${ }^{21}$ For a demonstration of the similarity see Fuhrer (1997), and Walsh (1998, pp. 224225).
} 
the value of $\phi_{1}$ we have used 0.03 and for the standard deviation of $\xi_{t}$ we used $0.002 .^{22}$

It remains to assign values to the other parameters, i.e., to complete calibration of the model. We do so with regard to quarterly U.S. data. For the IS sector we adopt the following values: $\sigma=5, \delta=0.025, \alpha=0.36$, $\rho=r^{s s}=0.005, \psi=0.125, \eta=3.42, \omega_{1}=0.78, \omega_{2}=0$, and $\omega_{3}=0.22 .{ }^{23}$ Thus we set $\sigma$ so as to imply an intertemporal elasticity of substitution in consumption of $1 / 5$, a magnitude consistent with various studies of the U.S. data. The depreciation rate and capital-share parameters, $\delta$ and $\alpha$, are quite conventional. The value of $\rho=r^{s s}$ implies an average real interest rate of 2 percent per year.

Calibration of the two parameters of the adjustment-cost function $C\left(x_{t}\right)$ is done to satisfy two assumptions. First, the total adjustment cost of investment is in steady state equal to approximately $1 \%$ of output, i.e., $\frac{C\left(x^{s s}\right)}{y^{s s}}=0.01$. Secondly, after analyzing impulse-response function and some, simulation experiments, we found that the semielasticity wrt $z_{t}$ in the investment function should be around 2.5 to yield business cycle fluctuations close to the empirical evidence in the sense that investment variability is several times the variability of consumption. These results will be reported and discussed in the next section. Then, we looked for the pair of values that imply both this semielasticity and $\frac{C\left(x^{s s}\right)}{y^{s s}}=0.01$, and consequently set $\eta=3.42$ and $\psi=0.125$.

The money demand or LM relation (20) shows that the interest rate. semi-elasticity equals $1 /\left(\gamma R^{s s}\right)$. Thus if we were to adopt $\gamma=7$ and $R^{s s}=$ $r^{s s}+\pi^{s s}=0.01$, we would obtain a value of 14.3 . But with $R_{t}$ used as the policy instrument, and with a separable period utility function, there is no need to calibrate the money demand equation as it plays no role in the evolution of most of the model's variables.

Finally, we need to assign magnitudes to the parameters of the stochastic disturbance processes. For the technology shock, which follows the process

\footnotetext{
${ }^{22}$ We have also conducted exercises using $\phi_{1}$ values of 0.05 and 0.0032 , which span a wide variety of estimates, and found that, there was little qualitative effect on the results.

${ }^{23}$ In the cases without adjustment costs, we have $\omega_{1}=0.7, \omega_{2}=0$, and $\omega_{3}=0.3$.
} 
(43) $\log A_{t}=\rho_{A} \log A_{t-1}+\varepsilon_{A t}$,

where $\varepsilon_{A t}$ is Gaussian white noise, we take $\rho_{A}=0.95$ and $\sigma_{\varepsilon_{A}}=0.006$, values that are typical in the real-business-cycle literature. ${ }^{24}$ The other nonzero serial correlation parameter pertains to the process (18) generating the consumption preference shock $v_{t}$; we use 0.3 for $\rho_{v}$ and a value of 0.003 for the standard deviation of the innovation to the disturbance in (19).

Regarding the variability of the monetary policy rule white-noise disturbance $\varepsilon_{R t}$, we have set $\sigma_{\varepsilon_{R}}=0.0017$ as estimated for the United States by McCallum and Nelson (1999b).

\section{Model Properties and Comparisons.}

We are now prepared to develop the paper's main results, which indicate how the model's properties depend upon the exogeneity vs. endogeneity of investment and the presence or absence of adjustment costs. The comparisons are developed for three model variants with both fully-flexible and slowly-adjusting prices using (42). In describing these properties we focus on impulse response functions for two shocks: the technology shock, $\varepsilon_{A t}$; and the random component of monetary policy, $\varepsilon_{R t}$.

Figures 1, 2, and 3 report paths for the variables $\widehat{y}_{t} ; \widehat{\bar{y}}_{t,} \pi_{t}-\pi^{s s}, \widehat{c}_{t}, \widehat{x}_{t}$, $\widehat{k}_{t}, f_{2 t}-f_{2}^{s s}, r_{t}-r^{s s}$, and $R_{t}-R^{s s}$ in response to a unit realization of the technology innovation $\varepsilon_{A t}$ when prices adjust fully within the period of the shock. The constant capital case is presented in Figure 1, the endogenous capital case with no adjustment costs is in Figure 2, and the endogenous capital case with investment adjustment costs is in Figure 3. As mentioned above, the "hat" figures represent deviations of these variables from their steady-state values. Thus a magnitude of 0.5 indicates that the variable's response is, in percentage terms, half as large as the shock.

\footnotetext{
${ }^{24}$ Actually, the most used figure in the literature for the standard deviation of the technology shock is 0.007 . For morc recent sample periods, however, the standard deviation of output is smaller than in past empirical studies, which might imply a reduction in "Solow residual" variability. As documented in Section 5 , we found $\sigma_{\hat{y}}=0.0135$ (i.c., 1.35 percent) for the period 1980.1-1999.4, whereas for the period 1975.1-1994.4 the value is significant,]y higher $\left(\sigma_{\hat{y}}=0.0173\right)$.
} 
Our first variant treats capital as a constant, therefore, there is no response of $\widehat{x}_{t}$ or $\widehat{k}_{t}$ to a unit realization of $\varepsilon_{A t}$. Consequently, the reponse of $\widehat{c}_{t}$ exceeds that of $\widehat{y}_{t}$, which jumps up by 0.64 and then gradually tails off. The marginal product of capital rises, as indicated by equation (39c), but the real rate of interest on securities, $r_{t}$, falls. This somewhat surprising response occurs in order to induce an increase in consumption so as to equate the current use of goods $\left(\widehat{y}_{t}=\left(c^{s s} / y^{s s}\right) \widehat{c}_{t}\right)$ to the enhanced capacity to produce goods $\left(\widehat{\bar{y}}_{t}\right)$. With $r_{t}$ thus given, the policy rule (41) and the Fisher relation $r_{t}=R_{t}-E_{t} \pi_{t+1}$ together determine inflation and the nominal interest rate. In this determination the presence of $0.8 R_{t-1}$ in the policy rule leads to a prolonged departure of $R_{t}$ from its steady-state value, and thereby influences the paths plotted.

In Figure 2 investment and capital are generated endogenously and there are no adjustment costs. Both investment and capital respond positively to the technology shock. The response of $\widehat{x}_{t}$ is about three times as large as for $\widehat{y}_{t}$ and about ten times as large as for $\widehat{c}_{t}$. As for capital, its peak in response to the technology impact is reached many quarters after the shock and has a size of $2 / 3$ of the shock, approximately. In this case the real interest rate equals the expected value of next period's marginal product of capital, adjusted by $\Theta$ and net of depreciation $\left(r_{t}=\Theta E_{t} f_{2 t+1}-\delta\right)$, so it must rise with the positive technology shock. Again, the policy rule and the Fisher relation determine paths of $R_{t}$ and $\pi_{t}$; in this case there is an upward blip in inflation.

The last result is reversed, however, in the case with adjustment costs (Figure 3). Here the presence of these costs of investing reduces the demand for investment by enough that its rise is about five times as large as for $\widehat{c}_{t}$. Accordingly, the value of $r_{t}$ does not need to rise to equate overall supply and demand; instead a slight fall is recorded. This leads to a temporary fall in the inflation rate in a manner similar to that of Figure 1. The response of the capital stock to the shock is somewhat muted (smaller) relative to that of Figure 2.

We need also to consider the effects of a shock to the policy rule, an upward blip in $\varepsilon_{R t}$. But for all the cases discussed thus far, the responses to $\varepsilon_{R t}$ are the same for each of the variables plotted. This is so because with flexible prices the model possesses monetary neutrality; thus the only 
effect is a one-time drop in the price level (a one-period negative blip in $\pi_{t}$ ). Interestingly, this drop is just sufficient so that the net response of $R_{t}$ is zero, even though the $R_{t}$ policy rule (41) is the equation shocked. This is so because with neutrality $r_{t}$ is not affected, and neither is expected future inflation. No figures are presented for these cases, therefore, because all three are alike, and in each there is no response for eight of the nine variables!

Now we turn to the variant of the model in which goods prices respond slowly, rather than instantaneously, to the shocks. In our opinion, this is the more realistic specification, although we readily admit that the particular price adjustment scheme adopted is open to objections. ${ }^{25}$ Figures 4 , 5 , and 6 report impulse response functions for both technology and policy rule shocks for the three cases: constant capital, endogenous investment without adjustment costs, and endogenous investment with adjustment costs (respectively). We begin with Panel A of each of the figures, which pertains to technology shocks. In Figure 4 , we see that $\widehat{\bar{y}}_{t}$ responds much as in Figure 1 and that $\widehat{x}_{t}$ and $\widehat{k}_{t}$ do not move at all (by assumption). For the remaining variables, the patterns are distinctly different from those in Figure 1. The responses are in the same directions but the movements are much more gradual and in some cases are smaller as well.

Next, in Panel A of Figure 5 we see that with endogenous investment. and no adjustment costs there is a very large spike (almost ten times the size of the shock) in $\widehat{x}_{t}$ in the period of the shock, followed by almost no departure from the steady-state level thereafter. Similar spikes appear in $\widehat{y}_{t}$ and $f_{2 t}-f_{2}^{s s}$.It is interesting to consider why the response of $x_{t}$ is so much greater than in Figure 2 even though inflation behavior seems to be not greatly different. The fact is that inflation behavior is just enough different that expected inflation rises in the period of the shock by almost as much as actual inflation, so $r_{t}$ does not rise appreciably. Therefore with no adjustment costs it is the case that $E_{t} f_{2 t+1}$ cannot jump up because of the arbitrage condition $r_{t}=\Theta E_{t} f_{2 t+1}-\delta$. Consequently, $E_{t} k_{t+1}$ must jump upward to keep $E_{t} f_{2 t+1}$ from rising in response to the technology shock. In other words, investment must be very large. With the recognition of adjustment

\footnotetext{
${ }^{25}$ As are all others. McCallım (1999c) argues that price adjustment is the most poorly understood aspect of macroeconomics; that there is great disagreement among scholars as to the formulation that most nearly satisfies the dual requirement of theoretical plausibility and empirical veracity.
} 
costs (Figure 6, Panel A), by contrast, the responses of $\widehat{x}_{t}, \widehat{y}_{t}$, and $f_{2 t}-f_{2}^{s s}$ are moderate and smooth. The maximum increase in $\widehat{k}_{t}$ is somewhat smaller than with no adjustment costs (compare to Figure 5).

Responses to policy rule shocks are even more interesting in these stickyprice cases. In Panel B of Figure 4 we see that an upward blip in $\varepsilon_{R t}$ brings about a similar-sized jump in $R_{t}$, which decays slowly. Inflation falls gradually and then slowly returns to its steady-state value. The magnitude of the fall is small enough, however, that the real interest rate $r_{t}$ behaves much like $R_{t}$. The temporary policy restriction drives $\widehat{y}_{t}, \widehat{c}_{t}$, and $f_{2 t}-f_{2}^{s s}$ down, after which all of these gradually return to their steady state values as time passes.

With endogenous investment but no adjustment costs, the response (in Panel B of Figure 5) to an $\varepsilon_{R t}$ blip is truly enormous, $\widehat{x}_{t}$ falling proportionally by more than 400 times (!) as much as the increase in $\varepsilon_{R t}$. Output also falls drastically (near 125 times) and even consumption drops by almost 2 times as much (in relative terms) as the shock. It seems clear that this case is highly unrealistic.

With adjustment costs, however, the responses are quite moderate. These are shown in Figure 6, Panel B. There $\widehat{c}_{t}$ falls by less than the shock magnitude, and investment by about eight times as much. The maximum fall in $\widehat{k}_{t}$ is (in percentage terms) about one half as much as the shock magnitude. Since output is a weighted average of consumption and investment, its response reaches an intermediate value-about two times the size of the shock. The effect on inflation of the brief policy tightening is not large, but is distinct and reaches a maximum after 4 quarters. While this may be a bit quicker than some practical analysts would say is realistic, the effect is still noticeable even after 10-12 quarters.

What is the verdict on the issue mentioned in the introduction, namely, whether the endogeneity vs. exogeneity of investment strongly affects the model's properties in other respects? If we take the sticky-price variant to be more realistic than that with fully flexible prices, and take the presence of adjustment costs to be more realistic than their absence, this question concerns the similarity of Figures 4 and 6 . In fact, as can be seen, there is considerable similarity between these two, in both the A and B panels. 
The magnitude of the output response is noticeably greater in the variablecapital case since it incorporates investment responses but the shapes of the seven plots excluding $\widehat{x}_{t}$ and $\widehat{k}_{t+1}$ are remarkably alike. Thus it, would appear that, judiciously utilized, the constant-capital - or exogenous investment analysis can provide a useful guide to the behavior of $\widehat{y}_{t}, \widehat{\bar{y}}_{t}, f_{2 t}, r_{t}$, and $R_{t}$. Obviously it cannot do so for $\widehat{c}_{t}-\widehat{y}_{t}$, nor for $\widehat{x}_{t}$ or $\widehat{k}_{t+1}{ }^{26}$

Another message provided by the exercise is that the presence or absence of price level stickiness in the model's formulation has rather strong effects on its response properties. These differences are sharper for responses to monetary shocks, but are also noticeable for responses to technology shocks - see Figures 3 and 6 (or 1 and 4).

In addition, the responses shown in Figure 5, for the sticky-price case with endogenous investment but no adjustment costs, are extremely large for the variables $\widehat{x}_{t}, \widehat{y}_{t}, \widehat{k}_{t+1}$, and $f_{2 t}-f_{2}^{s s}-$ especially in response to monetary shocks. Reliance on any single sticky-price specification is risky, without a robustness study. Nevertheless, the results in Figure 5 are so implausible that we are inclined to suggest that the inclusion of investment adjustment costs (or some other sluggishness mechanism) ${ }^{27}$ is virtually mandatory for models with endogenous investment and sticky prices.

We have also obtained some stochastic simulation results to illustrate the models' properties in another fashion and to provide a stringent check on their realism. The models with constant capital (Model 1), with endogenous investment and no adjustment cost (Model 2), and with endogenous investment and decreasing returns to scale adjustment costs (Model 3) were simulated using the sticky-price specification (42) and the calibration described in Section 4 . There were 200 observations in each simulation. Standard deviations, coefficients of correlation, and coefficients of autocorrelation were calculated for the main variables of the models. The experiment was repeated 200 times and the resulting averaged statistics are as reported in the following tables:

\footnotetext{
${ }^{26}$ Much the same can be said for the flexible-price variant of the model, as can be seen from Figures 1 and 3.

${ }^{27}$ Such as the Kydland and Prescott (1982) time-to-build mechanism, as mentioned above.
} 
Table 2

\begin{tabular}{cccccc}
\multicolumn{7}{c}{ Standard deviations (in percentage units). } \\
& Model 1 & Model 2 & Model 3 & US data & \\
$\sigma^{28}$ & EMU data ${ }^{29}$ \\
$\sigma_{\widehat{y}}$ & 1.00 & 22.02 & 1.56 & 1.35 & 0.84 \\
$\sigma_{\widehat{c}}\left(\sigma_{\widehat{c}} / \sigma_{\widehat{y}}\right)$ & $1.42(1.42)$ & $1.53(0.07)$ & $1.02(0.65)$ & $0.77(0.57)$ & $0.74(0.88)$ \\
$\sigma_{\widehat{x}}\left(\sigma_{\widehat{x}} / \sigma_{\widehat{y}}\right)$ & $0(0)$ & $72.77(3.30)$ & $4.00(2.56)$ & $4.00(2.96)$ & $2.52(3.00)$ \\
$\sigma_{\widehat{x}} / \sigma_{\widehat{c}}$ & 0 & 47.56 & 3.92 & 5.19 & 3.41
\end{tabular}

Table 3

Coefficients of correlation.

$\begin{array}{cccccc} & \text { Model 1 } & \text { Model 2 } & \text { Model 3 } & \text { US data } & \text { EMU data } \\ \rho_{\widehat{y}_{t}, \hat{c}_{t}} & 1 & 0.22 & 0.92 & 0.84 & 0.76 \\ \rho_{\hat{y}_{t}, \widehat{x}_{t}} & 0 & 0.99 & 0.94 & 0.91 & 0.92 \\ \rho_{\hat{c}_{t}, \widehat{x}_{t}} & 0 & 0.17 & 0.75 & 0.79 & 0.81\end{array}$

Table 4

\begin{tabular}{cccccc}
\multicolumn{7}{c}{ Coefficients of autocorrelation. } \\
Model 1 & Model 2 & Model 3 & US data & EMU data \\
$\rho_{\hat{y}_{t}, \widehat{y}_{t-1}}$ & 0.88 & -0.20 & 0.87 & 0.82 & 0.79 \\
$\rho_{\hat{c}_{t}, \bar{c}_{t-1}}$ & 0.88 & 0.89 & 0.81 & 0.78 & 0.76 \\
$\rho_{\widehat{x}_{t}, \widehat{x}_{t-1}}$ & 0 & -0.21 & 0.86 & 0.83 & 0.87
\end{tabular}

The simulation results lead to basically the same conclusion as obtained from the impulse response functions. When capital is endogenously introduced, some sort of sluggishness mechanism such as adjustment costs must be included to avoid excessive variability of investment. Indeed, the introduction of adjustment costs diminishes the standard deviation of investment by more than 15 times! (see Table 2).

\footnotetext{
${ }^{28}$ Quarterly observations were obtained for the US economy during the period 1980.11999.4. Output is Real GDP, consumption is Real Personal Consumption Expenditures on nondurable goods, and investment is Real Fixed Private Domestic: Investment. All the original series are expressed in chained 1996 US dollars and seasonally adjusted. To calculate the statistics, each series was logged and detrended using the Hodrick-Prescott filter $(\lambda=1600)$ as is common in the literature. Source: US Department of Commerce, Bureau of Economic Analysis.

${ }^{29}$ Output is measured by the real Gross Domestic Product. Consumption definition is real Private Final Consumption Expenditures whereas investment is real Gross Fixed Capital Formation. The sample period and the way of calculating the statistics are the same as for US data. Source: area-wide model data base, European Central Bank.
} 
As for the coefficients of correlation and autocorrelation, our model with adjustment costs again matches the empirical evidence reasonably well. By contrast, the model without adjustment costs generates too little contemporaneous co-movement of consumption and output and very low (even negative!) serial correlation in output and investment (see. Tables 3 and 4).

\section{Extensions.}

In this section we introduce a variant of the adjustment cost specification used above, a variant in which the unit cost of installing capital depends positively on the ratio $x_{t} / k_{t}$, i.e., $\frac{C\left(x_{t}, k_{t}\right)}{x_{t}}=h\left(x_{t} / k_{t}\right)$, with the properties $h^{\prime}()>$. and $2 h^{\prime}()+.\delta h^{\prime \prime}()>$.0 . Thus, the total adjustment cost of investment in period $t$ varies with both $x_{t}$ and $k_{t}$ :

$$
C\left(x_{t}, k_{t}\right)=x_{t} h\left(x_{t} / k_{t}\right) .
$$

With this functional form, the production function including adjustment costs is homogeneous of degree 1 , implying constant returns to scale. As a consequence, the ratio $\frac{C\left(x^{s s}, k^{s s}\right)}{y^{s s}}$ is independent of the size of the production plant. Moreover, Hayashi (1982) demonstrates that the average value of Tobin's $q$ is equal to its marginal value under this specification. The theoretically attractive features of this representation have led it to be used with some frequency in the literature (e.g., Abel and Blanchard (1983), Blanchard and Fisher (1989, p. 59), Obstfeld and Rogoff (1997), and Jermann (1998)). Assuming the functional form $h\left(x_{t} / k_{t}\right)=\widetilde{\psi}\left(x_{t} / k_{t}\right)^{\tilde{\eta}}$, one obtains

$$
C\left(x_{t}, k_{t}\right)=\widetilde{\psi} \frac{x_{t}^{\tilde{\eta}+1}}{k_{t}^{\tilde{\eta}}}
$$

in which $\widetilde{\eta}=1$ represents the case with quadratic adjustment costs. Calculating $C_{1}\left(x_{t}, k_{t}\right)$ and $C_{2}\left(x_{t+1}, k_{t+1}\right)$, and substituting the results in place of $C^{\prime}\left(x_{t}\right)$ and $(1-\delta) C^{\prime}\left(x_{t+1}\right)$ in equation (33) of our model with endogenous investment, one obtains

$$
\begin{aligned}
& \widetilde{\psi}(\tilde{\eta}+1)\left(\frac{x_{t}}{k_{t}}\right)^{\tilde{\eta}}=\Theta E_{t} f_{2 t+1}-\delta-r_{t}+(1-\delta) \widetilde{\psi}(\tilde{\eta}+1)\left(\frac{E_{t} x_{t+1}}{k_{t+1}}\right)^{\tilde{\eta}}+ \\
& \widetilde{\psi} \tilde{\eta}\left(\frac{E_{t} x_{t+1}}{k_{t+1}}\right)^{\tilde{\eta}+1}
\end{aligned}
$$


After loglinearization, the latter is approximated by ${ }^{30}$

(46) $\widehat{x}_{t}=\frac{1}{1+\delta} E_{t} \widehat{x}_{t+1}+\frac{1}{(1+\delta) \widetilde{\eta} C_{1}\left(x^{s s}, k^{s s}\right)}\left(\Theta E_{t} f_{2 t+1}-\delta-r_{t}\right)+\frac{\delta}{1+\delta} \widehat{k}_{t:}$

with $C_{1}\left(x^{s s}, k^{s s}\right)=\widetilde{\psi}(\tilde{\eta}+1) \delta^{\tilde{\eta}}$. It will be noted that the appearance of the investment equation (46) is quite similar to the relation (35) obtained in Section 3 for our previous adjustment cost specification. In both of these, current period investment is positively affected by the expected future (adjusted) premiums for the physical asset over the financial asset. The semi-elasticity with respect to the expected premium is determined by the parameters of the adjustment cost function. There is also a component in (46) that did not appear in the investment equation (35): the value of capital in use in the current period $\widehat{k}_{t}$ now enters the investment equation separately with a positive coefficient $\frac{\delta}{1+\delta}$. With that coefficient, however, the quantitative significance of $\widehat{k}_{t}$ will be very small ${ }^{31}$ Therefore, the two investment equations (46) and (35) would appear to be virtually operationally equivalent. if they are calibrated according to the same criteria (i.e., to yield the same semielasticity wrt the premium and the same fraction of output used up by adjustment costs). In this case, impulse response functions and simulation results would then be very similar for both adjustment cost specifications. Thus, the same conclusions as reached in Section 5 would be applicable to our endogenous investment model with the constant returns to scale adjustment cost specification (44).

Accordingly, let us now use the same criteria as before to calibrate the values of the parameters $\widetilde{\psi}$ and $\widetilde{\eta}$ in (44). That is, the selected figures will be chosen to imply a semi-elasticity of investment with respect to the expected premium equal to 2.5 and a total adjustment cost equal to $1 \%$ of output in the steady state. Values of the semielasticity for various $\widetilde{\eta}$ and $\widetilde{\psi}$ values are shown in Table 5. On the basis of the implied relationship, we assign $\widetilde{\psi}=524.6$ and $\tilde{\eta}=2.55$. Therefore, the quadratic adjustment cost specification, with $\widetilde{\eta}=1$, is far from our calibrated value based on business cycle properties. If

\footnotetext{
(29).

${ }^{30}$ Note that we used $\frac{x^{s s}}{k^{s s}}=\delta$ and $\widehat{k}_{t+1}=\delta \widehat{x}_{t}+(1-\delta) \widehat{k}_{t}$ from the investment definition

${ }^{31}$ After calibration, the semi-elasticity of the physical asset premium is 2.5 and the semi-elasticity of $k_{t}$ is $\frac{0.025}{1.025}=0.024$. The former is more than 100 times the latter.
} 
nevertheless it were set, at $\tilde{\eta}=1$, then we would be required to have either a very high semi-elasticity with respect to $z_{t}$, i.e., too much variability of investment, or an implausibly large magnitude of the total adjustment cost in terms of output, i.e., a value of $\frac{C\left(x^{s s}, k^{s s}\right)}{y^{s s}}$ that is too large..$^{32}$

Based on our assigned values of $\widetilde{\psi}=524.6$ and $\widetilde{\eta}=2.55$, impulse response functions corresponding to the constant returns to scale case are shown as dotted lines in Figure 6. The plots are almost indistinguishable from those of the solid lines, confirming that in fact the two adjustment-cost functions yield very similar results when calibrated according to the same criteria, ${ }^{33}$

\section{Table 5}

Semi-elasticity wrt the real asset expected premium in the investment equation (46).

$\begin{array}{cccc} & \widetilde{\psi}=250 & \widetilde{\psi}=500 & \widetilde{\psi}=750 \\ \widetilde{\eta}=2 & 1.04 & 0.52 & 0.35 \\ \tilde{\eta}=2.5 & 4.51 & 2.26 & 1.50 \\ \tilde{\eta}=3 & 20.8 & 10.4 & 6.94\end{array}$

One of our more striking findings is that the absence of capital adjustment, costs leads, with sticky prices, to implausibly large responses of both investment and output, especially with monetary policy shocks. It is natural to ask whether this result is sensitive to our assumption that labor employment is not constrained within each period by the quantity currently preferred by households-i.e., that labor is demand determined. To investigate the effect. of relaxing this assumption, the model can be altered so as to (i) incorporate elastic labor supply by including leisure in the utility function, (ii) require the relevant first-order condition of the household to be satisfied in each period,

\footnotetext{
${ }^{32}$ When we have the case $\tilde{\eta}=1$ and we maintain the $\frac{C\left(x^{s s}, k^{s s}\right)}{y^{4 n}}=0.01$ criterion the implied semi-elasticty of the real asset premium $z_{t}$ in the investment equation (46) is 11.31 (more than 4 times the calibrated figure). Likewise, for the case $\tilde{\eta}=1$ and maintining the semi-elasticity of $z_{t}$ in (46) equal to the calibrated figure 2.5 , we find $\frac{C\left(x^{s s}, k^{* 4}\right)}{y^{s s}}=0.0403$ (more than 4 times the calibrated figure).

${ }^{33}$ The constant returns to scale case reports slightly higher responses to shocks. Compared to the decreasing returns to scale case, investment rises by approximately $3 \%$ more when there is a technology shock and falls by $1 \%$ more (almost indistinguishable) when there is a shock to the monetary policy rule.
} 
and (iii) make the price adjustment relation's gap variable pertain to real marginal cost (as in Gali and Gertler (1999)) rather than to output. ${ }^{34}$ With these modifications, a constant-elasticity labor supply specification with elasticity of 1.0 (and average time spent working of $1 / 3$ per period) leads to $x_{t}$ and $y_{t}$ spikes of about -150 and -50 , in comparison with the -400 and -120 values shown in Figure 5B. Analogous magnitudes with a labor supply elasticity of 2.0 are -230 and -70 , while with an elasticity of 0.5 they are -90 and -30 . Thus the responses continue to be implausible, if less dramatically so than with our basic setup. We believe, in any case, that our basic specification is more realistic, i.e., that quarter-by-quarter fluctuations in labor input are governed by institutional arrangements (labor contracts, perhaps implicit) that have producers unilaterally determine employment in each period, with labor supply preferences affecting the natural-rate reference values that current gap variables (and therefore price adjustments) refer to.

\section{Conclusions.}

In the foregoing sections we have explored the inclusion of endogenous investment decisions in dynamic optimizing models that are expressed in an expectational IS-LM framework. Such models, with sticky prices, have been used in much recent monetary-policy research but usually with fixed or exogenous capital. We have found that capital/investment decisions can be endogenized readily without undue complexity or loss of the IS-LM-style conceptual framework that is attractive heuristically. Specifically, we have found that endogenous investment in the presence of capital adjustment ("installation") costs can be calibrated to yield reasonably realistic dynamic behavior using either of two simple adjustment-cost functions, one of which features constant (and the other decreasing) returns to scale in production. Our calibration suggests, however, that a quadratic specification for the adjustment cost function, which has been used by various researchers, is apparently inappropriate. Specifically, it implies an excessively large responsiveness of investment to monetary policy actions, at least under the realistic assumption that these are implemented with an interest rate instrument.

The paper's analysis also yields two additional conclusions that are quite noteworthy. First, models with endogenous capital/investment choices but

\footnotetext{
${ }^{34}$ Without this third modification, (i) and (ii) would merely call for altered fluctuations in the real wage rate with no effect on output or investment.
} 
no adjustment costs imply highly unrealistic responses to monetary policy surprises under the assumption that price-level stickiness obtains. Such models appear to be less appropriate than ones with exogenous investment. Second, although explicit inclusion of endogenous investment is both attractive and readily accomplished, analyses with exogenous capital are not drastically misleading with respect to the cyclical behavior of output and real interest rates. Thus such models can, if judiciously utilized, be useful for some types of business-cycle and monetary policy analysis. 


\section{APPENDIX}

Steady state analysis in a Sidrauski-type model when adjustment cost of installing capital goods are considered.

Let us take the capital first order condition with adjustment costs of investment (32) in steady state. Recalling that $r^{s s}=\rho$, we obtain

$$
1+\rho=\frac{1+\Theta f_{k}-\delta+(1-\delta) C^{\prime}}{1+C^{\prime}},
$$

which after some algebra implies that the steady state marginal product of capital becomes

$$
f_{k}=\frac{1}{\Theta}\left[(\rho+\delta)\left(1+C^{\prime}\right)\right] .
$$

Note that $f_{k}-\delta>\rho$ and thus there is less capital employed than in the perfect competition setup with endogenous investment and no adjustment costs in which $f_{k}-\delta=\rho$. Furthermore, even in the absence of the inefficiency due to monopolistic competition (i.e., $\Theta=1$ ), the presence of the adjustment cost creates a deviation of the marginal product of capital from the real rate of interest.

As for the stock of capital in a steady state, $k$, we can illustrate how it is determined by using a Cobb-Douglas technology in the previous expression:

$$
\alpha k^{\alpha-1}=\frac{1}{\Theta}\left[(\rho+\delta)\left(1+C^{\prime}\right)\right]
$$

After rearrangment, the result is

$$
k=\left(\frac{\alpha \Theta}{(\rho+\delta)\left(1+C^{\prime}\right)}\right)^{\frac{1}{1-\alpha}}
$$

Thus the stock of capital depends positively on the capital share in the production function $\alpha$ and on the mark-up factor $\Theta$, and negatively on the rate of depreciation $\delta$, the rate of intertemporal preference $\rho$, and the steadystate marginal adjustment cost $C^{\prime}=C^{\prime}\left(\delta k_{i}\right)$. 


\section{REFERENCES}

Abel, Andrew B., 1983. "Optimal Investment Under Uncertainty," American Economic Review 73 (March), 228-233.

Abel, Andrew B., and Olivier J Blanchard, 1983. "An Intertemporal Equilibrium Model of Saving and Investment," Econometrica 51 (May), 575-692.

Blanchard, Olivier J., and Stanley Fischer, 1989. Lectures on Macroeconomics. MIT Press, Cambridge, MA.

Calvo, Guillermo A., 1983. "Staggered Pricing in a Utility-Maximizing Framework," Journal of Monetary Economics 12 (Sept.), 383-396.

Casares, Miguel, 2000. "Dynamic Analysis in an Optimizing Monetary Model with Transaction Costs and Endogenous Investment," Doctoral Thesis, 61103.

Clarida, Richard, Jordi Gali, and Mark Gertler, 1998. "Monetary Policy Rules in Practice: Some International Evidence," European Economic Review 42 (June), 1033-1067.

,$--\frac{}{-}$, and,- 1999 . "The Science of Monetary Policy: A New Keynesian Perspective," Journal of Economic Literature 37 (December), 16611707.

Dixit, Avinash K., and Joseph E. Stiglitz, 1977. "Monopolistic Competition and Optimum Product Diversity," American Economic Review 67, 297-308.

Eisner, Robert, and Robert Strotz, 1963. "Determinants of Business Investment," Impacts of Monetary Policy. Prentice-Hall Pub. Co., Englewood Cliffs, NJ.

Estrella, Arturo, and Jeffrey C. Fuhrer, 1998, "Dynamic Inconsistencies: Counterfactual Implications of a Class of Rational Expectations Models," Federal Reserve Bank of Boston Working Paper No. 98-5.

Fuhrer, Jeffrey C., and George R. Moore, 1995. "Inflation Persistence," Quarterly Journal of Economics 109, 127-159. 
Fuhrer, Jeffrey C.,1997. "The (Un)importance of Forward-Looking Behavior in Price Specifications," Journal of Money, Credit, and Banking 29, 338-350.

Galí, Jordi, and Mark Gertler, 1999. "Inflation Dynamics: A Structural Econometric Analysis," Journal of Monetary Economics 44 (October), 195222.

Goodfriend, Marvin, and Robert G. King, 1997, "The New Neoclassical Synthesis and the Role of Monetary Policy." In NBER Macroeconomics Annual 1997, B. M.Bernanke and J. J. Rotemberg, eds. MIT Press, Cambridge, MA.

Hayashi, Fumio, 1982. "Tobin's Marginal and Average q: A Neoclassical Interpretation," Econometrica 50 (January), 213-224.

Jeanne, Olivier, 1998. "Generating Real Persistent Effects of Monetary Shocks: How much Nominal Rigidity Do We Need?," European Economic Review, 42 (June), 1009-1032.

Jermann, Urban J., 1998. "Asset Pricing in Production Economies," Journal of Monetary Economics 41, 257-275.

Kerr, William, and Robert G. King, 1996. "Limits on Interest Rate Rules in the IS Model," Federal Reserve Bank of Richmond Economic Quarterly 82 (Spring), 47-75.

Kimball, Miles S., 1995. "The Quantitative Analytics of the Basic Neomonetarist Model," Journal of Money, Credit, and Banking 27 (Nov.,Pt. 2), 1241-1277.

King, Robert G., and Alexander L. Wolman, 1996. "Inflation Targeting in a St. Louis Model of the 21st Century," Federal Reserve Bank of St. Louis Review 78,83-107.

— and - 1999. "What Should the Monetary Authority Do When Prices are Sticky?" In Monetary Policy Rules, J. B. Taylor, ed. University of Chicago Press, Chicago, IL.

Kollman, Robert, 1997. "The Exchange Rate in a Dynamic Optimizing Current Account Model with Nominal Rigidities: A Quantitative Investigation," Working Paper 97-7, International Monetary Fund. 
Koenig, Evan, 1989. "A Simple Optimizing Alternative to Traditional IS-LM Analysis," manuscript, Federal Reserve Bank of Dallas.

Kydland, Finn E., and Edward C. Prescott, 1982. "Time to Build and Aggregate Fluctuations," Econometrica 50 (November), 1345-1370.

Lucas, Robert E., Jr., and Edward C. Prescott, 1972. "Investment Under Uncertainty," Econometrica 39 (September), 659-681.

McCallum, Bennett T., 1999a. "Analysis of the Monetary Transmission Mechanism: Methodological Issues," NBER W.P. 7395.

_ 1999b. "Theoretical Analysis Regarding a Zero Lower Bound on Nominal Interest Rates," NBER W.P. 7677.

—_, 1999c. "Issues in the Design of Monetary Policy Rules," in Handbook of Macroeconomics, J.B. Taylor and M. Woodford, eds. NorthHolland Pub. Co., Amsterdam.

McCallum, Bennett T., and Edward Nelson, 1999a. "An Optimizing IS-LM Specification for Monetary Policy and Business Cycle Analysis,"

Journal of Money, Credit, and Banking 31 (August, part 1), 296-316.

and - , 1999b. "Performance of Operational Policy Rules in an Estimated Semiclassical Structural Model," in Monetary Policy Rules, J.B. Taylor, ed. University of Chicago Press, Chicago IL.

Obstfeld, Maurice, and Kenneth Rogoff, 1996. Foundations of International Macroeconomics. MIT Press, Cambridge, MA.

Rotemberg, Julio J., 1982. "Monopolistic Price Adjustment and Aggregate Output," Review of Economic Studies 44, 517-531.

Rotemberg, Julio J., and Michael Woodford, 1997. "An Optimizing-Based Econometric Framework for the Evaluation of Monetary Policy,"

NBER Macroeconomics Annual 1997, B.M. Bernanke and J.J. Rotemberg, eds. MIT Press, Cambridge, MA.

— and - - 1999. "Interest Rate Rules in an Estimated Sticky Price Model," in Monetary Policy Rules, J.B. Taylor, ed. University of Chicago Press, Chicago, IL. 
Sbordone, Argia, 1998, "Prices and Unit Labor Costs: A New Test of Price. Stickiness," Working Paper, Rutgers University.

Taylor, John B., 1993. "Discretion Versus Policy Rules in Practice." Carnegie Rochester Conference Series on Public Policy 39 (Nov.), 195-214.

Tobin, James, 1969. "A General Equilibrium Apprach to Monetary Theory," Journal of Money, Credit, and Banking 1 (February), 15-29.

Uhlig, Harald, 1999. "A Toolkit for Analyzing Nonlinear Dynamic Stochastic Models Easily," Computational Methods for the Study of Dynamic Economics, Ramón Marimón and Andrew Scott, (eds.), Oxford University Press.

Walsh, Carl E., 1998. Monetary Theory and Policy. MIT Press, Cambridge, MA.

Woodford, Michael, 1995. "Price-Level Determinacy Without Control of a Monetary Aggregate," Carnegie-Rochester Conference Series on Public Policy 43 (Nov.), 1-46.

—, 1999. "Interest and Prices", manuscript.

Yun, Tack, 1996: "Nominal Price Rigidity, Money Supply Endogenity, and Business Cycles," Journal of Monetary Economics 37, 345-370. 

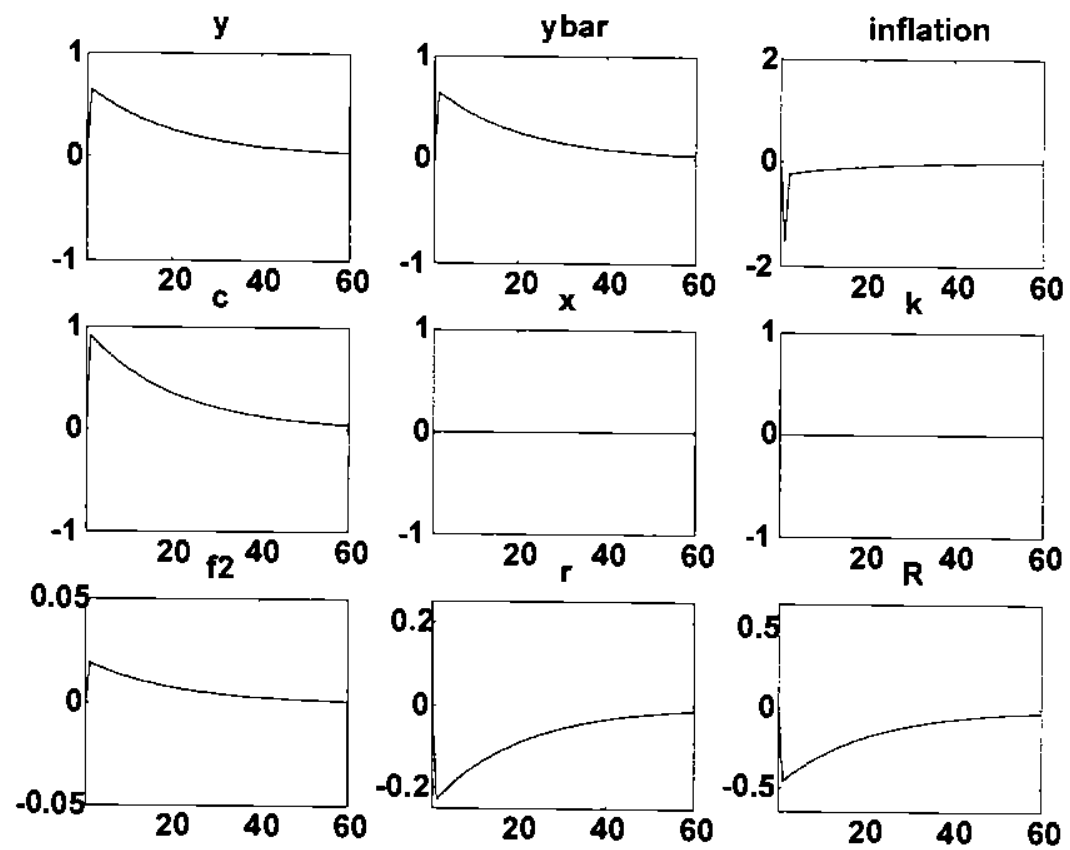

Figure 1. Fully-flexible prices. Constant capital. Technology unit shock. 

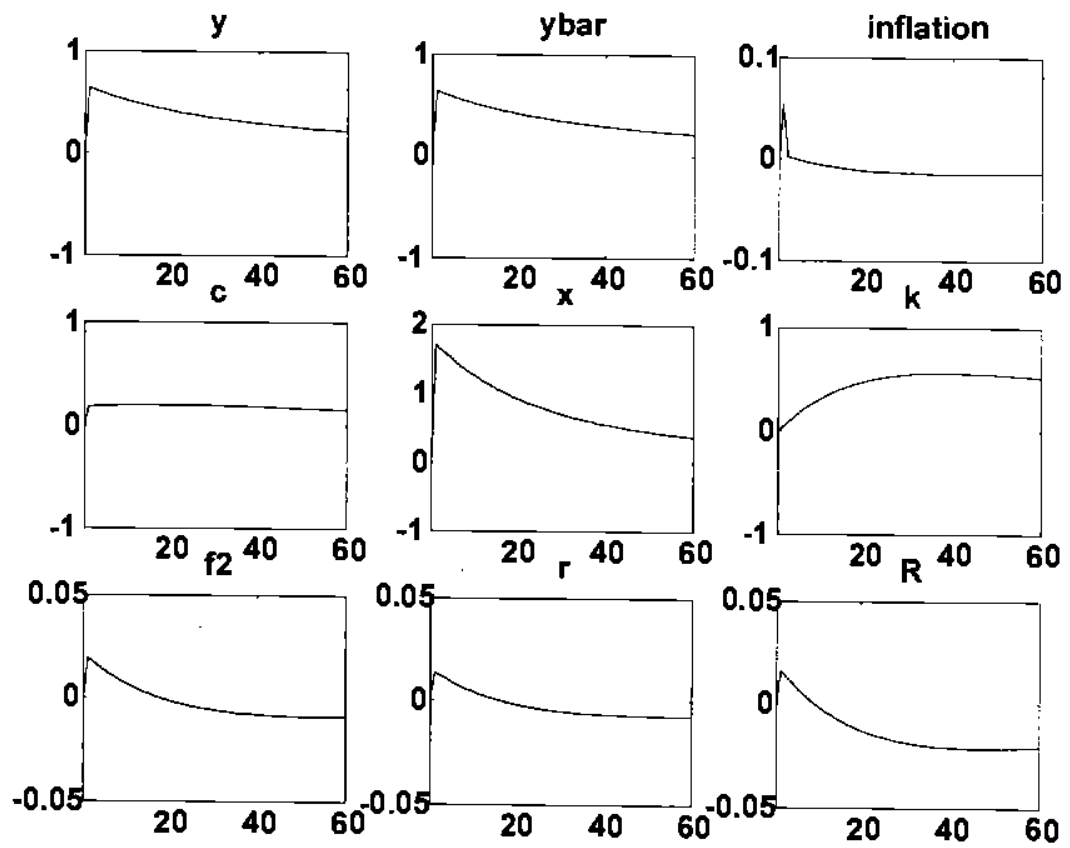

Figure 2. Fully-flexible prices. Variable capital and no adjustment costs. Technology unit shock. 

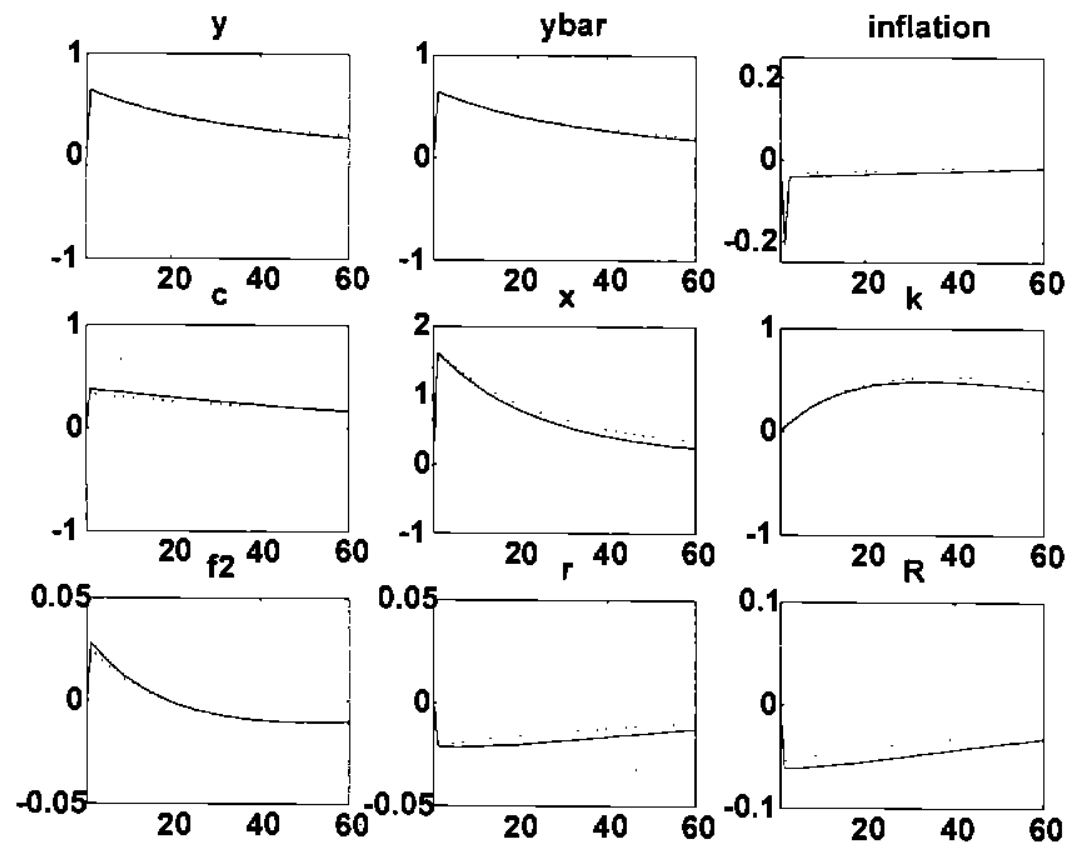

Figure 3. Fully-flexible prices. Variable capital. Adjustment costs on investment with either decreasing returns to scale (solid lines) or constant returns to scale (dotted line). Technology unit shock. 

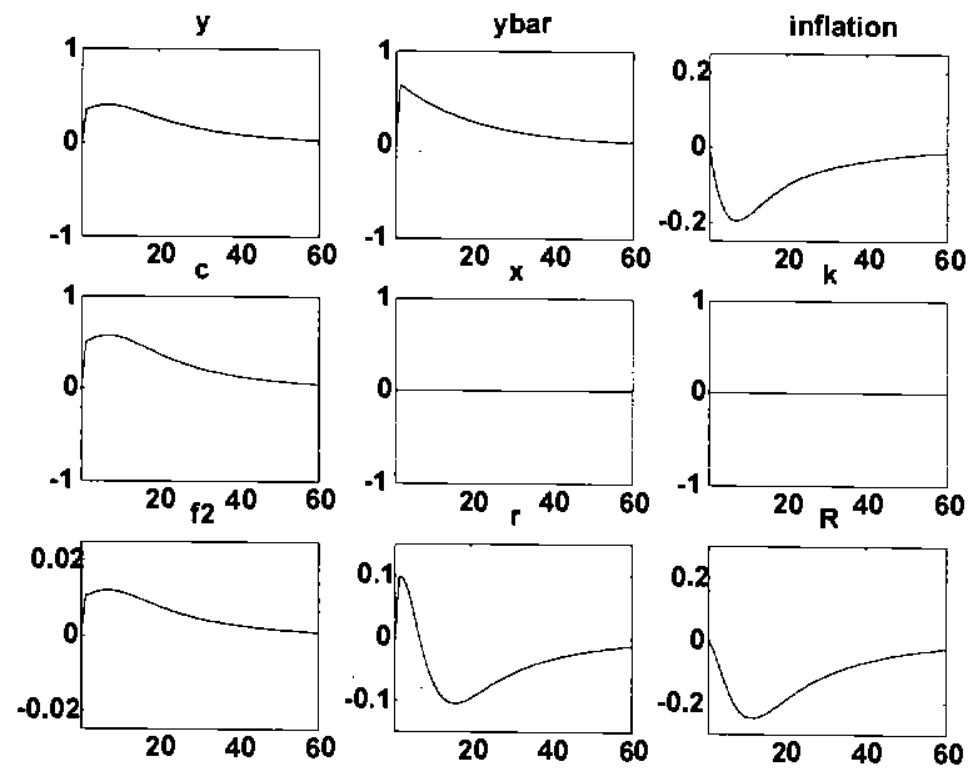

Figure 4. Panel A. Sticky prices. Constant capital. Technology unit shock.
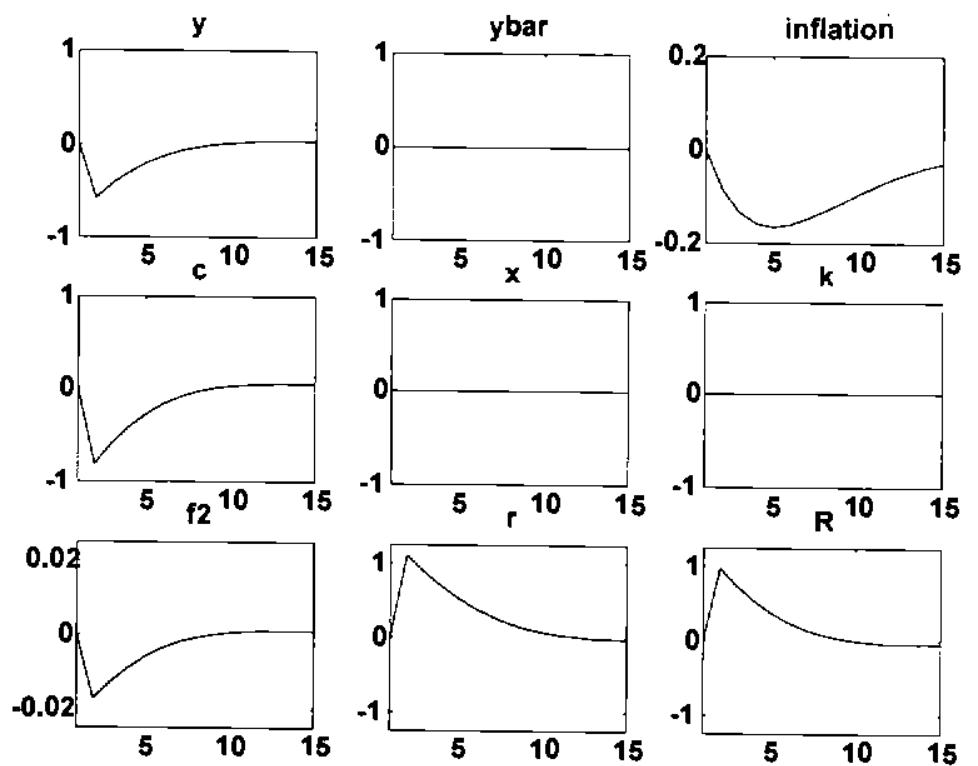

Figure 4. Panel B. Sticky prices. Constant capital. Monetary Policy Rule unit shock. 

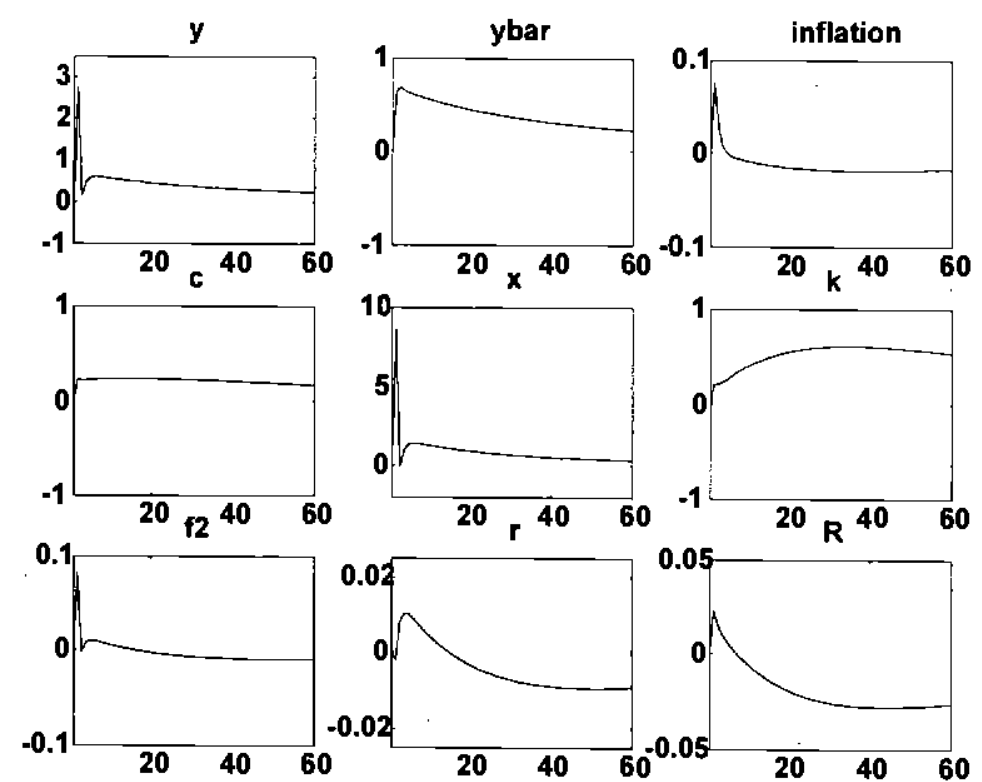

Figure 5. Panel A. Sticky prices. Variable capital. No adjustment costs.

Technology unit shock.
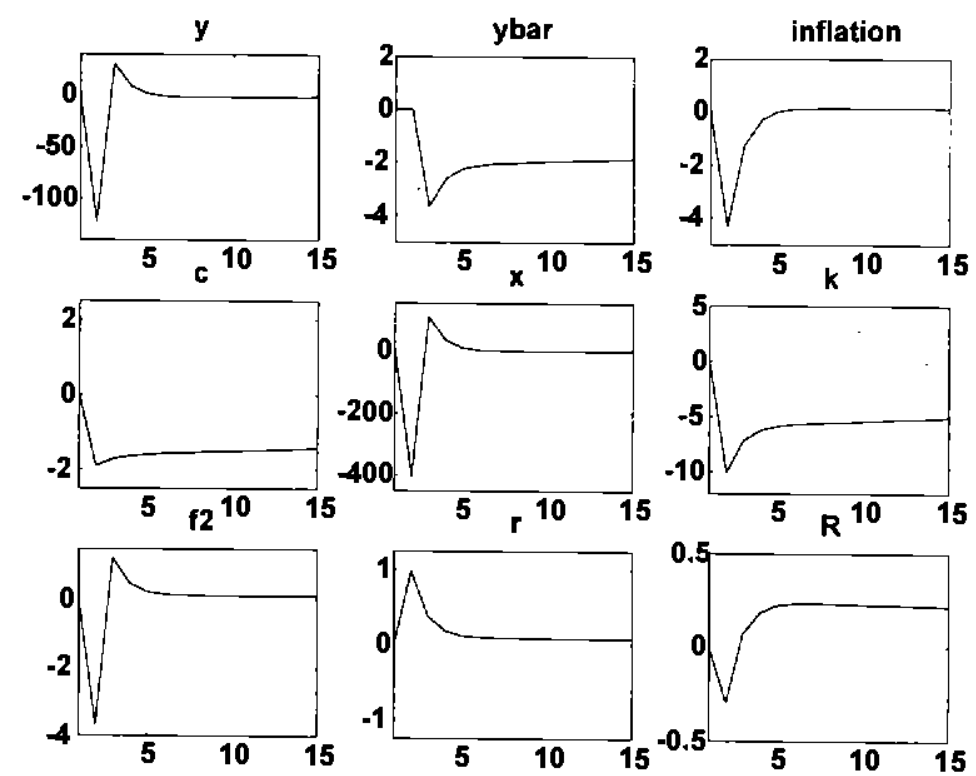

Figure 5. Panel B. Sticky prices. Variable capital. No adjustment costs. Monetary policy rule unit shock. 

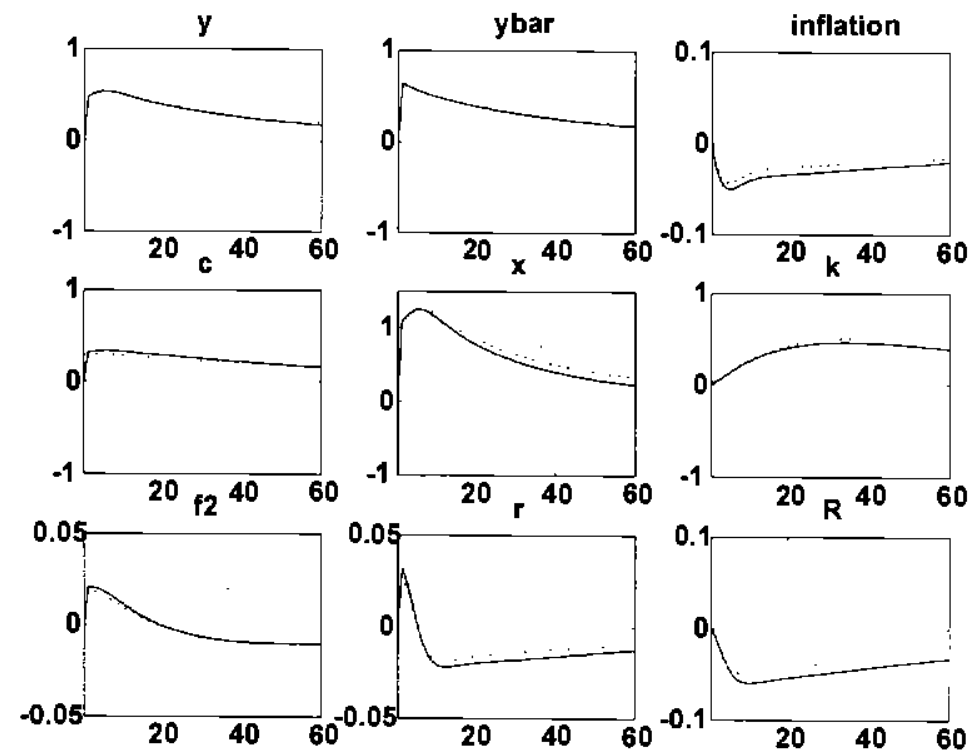

Figure 6. Panel A. Sticky prices. Variable capital. Adjustment costs on investment with either decreasing returns to scale (solid lines) or constant. returns to scale (dotted line). Technology unit shock.
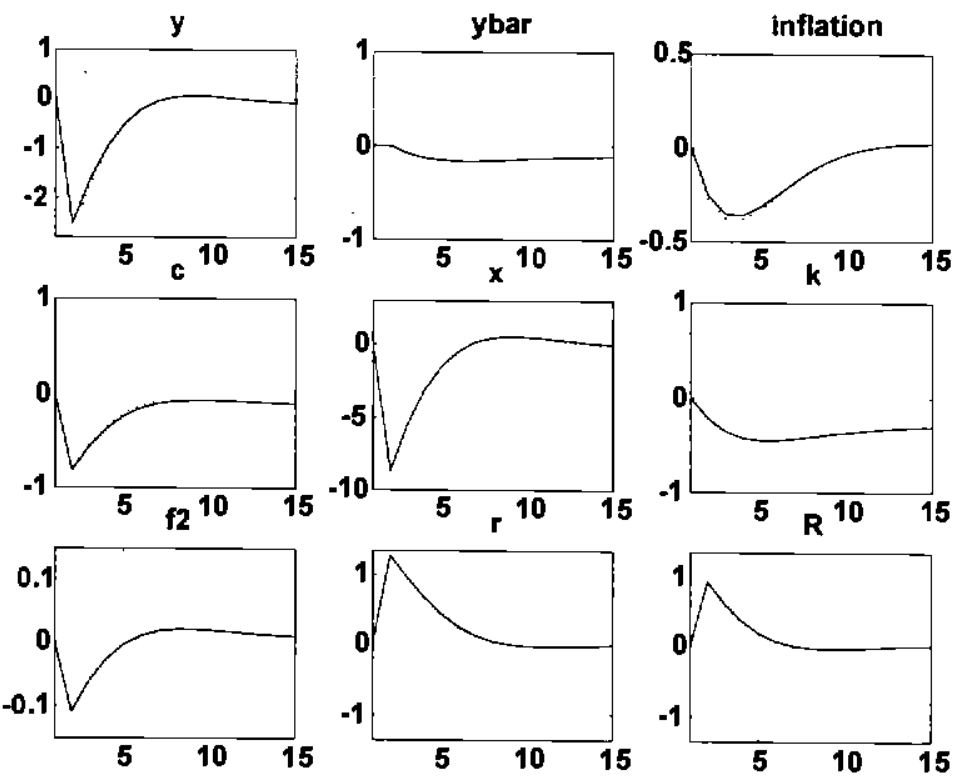

Figure 6. Panel B. Sticky prices. Variable capital. Adjustment costs on investment with either decreasing returns to scale (solid lines) or constant returns to scale (dotted line). Monetary Policy Rule unit shock. 